\title{
Análise da Influência do Uso da Terra no Microclima Urbano: Caso Irati-PR
}

\author{
Paulo Costa de Oliveira Filho ${ }^{1}$, Kelly Geronazzo Martins ${ }^{1}$, Gabriela Evaristo ${ }^{1}$, \\ Aparecido Ribeiro de Andrade ${ }^{1}$, Charles Andrey da Silva ${ }^{1}$, Amanda Maciel ${ }^{1}$, \\ Gabriela Diedrisch Barbosa ${ }^{1}$
}

${ }^{1}$ Departamento de Engenharia Ambiental - DENAM, Universidade Estadual do Centro-Oeste - UNICENTRO, Irati/PR, Brasil

\begin{abstract}
RESUMO
A redução das áreas verdes urbanas e o consequente aumento das áreas construídas é um dos temas mais discutidos atualmente. Tanto a dinâmica do uso do solo urbano quanto de mudanças climáticas podem comprovar relações entre diversos usos e ocupações do solo e suas consequências para o microclima local. Este trabalho apresenta uma avaliação da influência do uso da terra no clima urbano em uma cidade de pequeno porte. Foram selecionados 4 pontos abrangendo o perímetro urbano de Irati, no estado do Paraná, com diferentes ocupações, e obtidas variáveis de temperatura e umidade relativa com uso de higrômetros adaptados em abrigos termométricos em 4 horários distintos durante 4 dias. A utilização de imagens orbitais de alta resolução possibilitou o mapeamento do uso do solo urbano de áreas de abrangência num raio de 350 metros dos pontos pré-selecionados. Os resultados comprovaram, estatisticamente, que o uso e ocupação do solo interferem nas variáveis climáticas obtidas.
\end{abstract}

Palavras-chave: sensoriamento remoto, áreas verdes urbanas, ilhas de calor.

\section{Analysis of Land Use Influence in Urban Microclimate: Irati-PR Case}

\begin{abstract}
The reduction of urban green areas and consequent increase of the built areas is one of the most widely discussed topics nowadays. Both the urban land use dynamics and the climate changes may prove relationships between different uses and land occupations and their consequences for the local microclimate. This paper presents an assessment of the land use influence in the urban climate in a small town. A total of 4 points covering the urban perimeter of Irati, Paraná, with different occupations were selected and temperature and humidity variables obtained with use of adapted hygrometers in thermometric shelter in 4 different times for 4 days. The use of high resolution satellite images enabled the mapping of urban land use in catchment areas within a radius of 350 meters of pre-selected points. The results statistically showed that the use and occupation of land interfere with the climate variables obtained.
\end{abstract}

Keywords: remote sensing, urban green areas, heat islands. 


\section{INTRODUÇÃO}

Os elementos de sensoriamento remoto, como as imagens orbitais e fotografias aéreas, são extremamente necessários para analisar os processos de planejamento e a reestruturação do meio urbano. Esses elementos concedem a visualização de origens e características das causas modificadoras dos espaços e a verificação da extensão e intensidade das mudanças causadas pelo homem (Rodriguez, 2000). Entre tais mudanças, as alterações de temperatura do meio urbano, chamadas de ilhas de calor, estão entre as de maior impacto (Ayoade, 1998). Tal fenômeno provém da elevação das temperaturas médias nos centros urbanos e da parte industrial. Isso acontece, principalmente, devido às diferenças de irradiação de calor entre as regiões construídas, as regiões com solo exposto ou com maior vegetação. A concentração de poluentes, maior nos centros urbanos, também é um fator causador desse impacto (Teza \& Baptista, 2005).

De fato, a urbanização altera o clima local, diminuindo ou eliminando as diferenças ocasionadas em determinado sítio, assim, áreas urbanas transformam o clima através da modificação nas superfícies, adicionando materiais mais condutivos de calor ou desenvolvendo atividades geradoras do mesmo (Lombardo, 1997). Na cidade de São Paulo, Lombardo (1985) encontrou temperaturas mais elevadas em regiões com maior quantidade de áreas construídas do que nas regiões periurbanas, e as diferenças de temperatura chegaram a $10{ }^{\circ} \mathrm{C}$. Entretanto, o mesmo autor afirma que em regiões onde há presença de água e áreas vegetadas as oscilações de temperatura no dia tendem a ser menores, além destas serem mais amenas que em áreas bastante urbanizadas. Essas diferenças podem ser explicadas pelo processo de fotossíntese e transpiração da vegetação, que retém radiação solar; da mesma forma, a água presente interfere no balanço de energia do ambiente pela elevada capacidade calorífica e pelo gasto de calor por evaporação.

A intensidade da ICU (ilha de calor urbana) e a sua dimensão espacial está associada à localização da cidade, forma e densidade das construções, além do tipo de materiais utilizados, das ações industriais, do clima local e da sucessão das situações sinóticas e tipos de tempo (Cantat, 2004). Nesse contexto, o presente estudo teve como objetivo comprovar o relacionamento entre o uso e ocupação do solo urbano e periurbano com as variáveis climáticas obtidas na cidade de Irati, Paraná.

\section{MATERIAL E MÉTODOS}

\subsection{Localização e caracterização da área de estudo}

O presente estudo foi realizado na cidade de Irati (Figura 1), entre as coordenadas geográficas $50^{\circ} 38^{\prime}$ e $50^{\circ} 40^{\prime}$ de longitude oeste e $25^{\circ} 28^{\prime}$ e $25^{\circ} 27^{\prime}$ de latitude sul, que está localizada a $150 \mathrm{~km}$ de Curitiba, na região Centro-Oeste do estado do Paraná e possui uma população de aproximadamente 58,937 habitantes

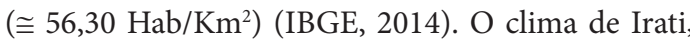
segundo a classificação de K é Cfb (clima temperado úmido com verão temperado), sua temperatura média máxima é de $24,2^{\circ} \mathrm{C}$ e a média mínima é de $11,0^{\circ} \mathrm{C}$, apresenta uma média mensal de precipitação em torno de 193,97mm e a umidade relativa do ar média mensal é de 79,58\% (IAPAR, 2014).

\subsection{Obtenção e análise das imagens orbitais}

A partir de imagens orbitais multiespectrais fusionadas do satélite Quickbird, com resolução espacial de $61 \mathrm{~cm}$, de agosto de 2011 foram pré-selecionadas quatro áreas amostrais com características bem distintas quanto à quantidade de área construída e de áreas verdes e corpos hídricos, dentro do perímetro urbano de Irati, Paraná. Metodologia semelhante foi adotada por Andrade et al. (2013).

A seguir, implementou-se em ambiente de sistema de informações geográficas (SIG), utilizando o aplicativo de domínio público SPRING versão 5.1.2, um modelo de dados para a espacialização dessas áreas a partir das imagens orbitais. Foram definidos pontualmente sobre as imagens quatro pontos para a instalação das miniestações meteorológicas e obtenção em campo das medições de temperatura e umidade relativa do ar. A partir de cada ponto central de cada região selecionada, foram delimitadas áreas de abrangência de 350 metros de raio, definindo-se as quatro áreas amostrais. As regiões escolhidas possuem as seguintes características: Área amostral 1, com bastante vegetação arbórea e rasteira; a área amostral 2, bem central, com alta concentração de áreas construídas e pouca vegetação; área amostral 3, média concentração 
de áreas verdes e corpos d'água; e área amostral 4, representando um perímetro residencial que segue um padrão de casas com jardins e quintais. Após a definição das áreas utilizadas no estudo, foi realizada a interpretação das imagens, dentro dos entornos das miniestações meteorológicas dos quatro pontos, através da representação e vetorização seguidas da classificação manual por associação em ambiente SIG. As seguintes classes foram definidas neste estudo: vegetação arbórea, vegetação rasteira, corpos d'água e área construída. Os índices de áreas verdes foram calculados através da razão das áreas verdes, que inclui as áreas arbóreas e vegetação rasteira, pela área total de cada amostra. Foram também calculados os índices de vegetação arbórea através da razão da área total arbórea pela área total de cada amostra.

\subsection{Coleta de dados meteorológicos}

As miniestações utilizadas para a obtenção das variáveis de temperatura e umidade relativa do ar foram constituídas de 4 higrômetros de leitura

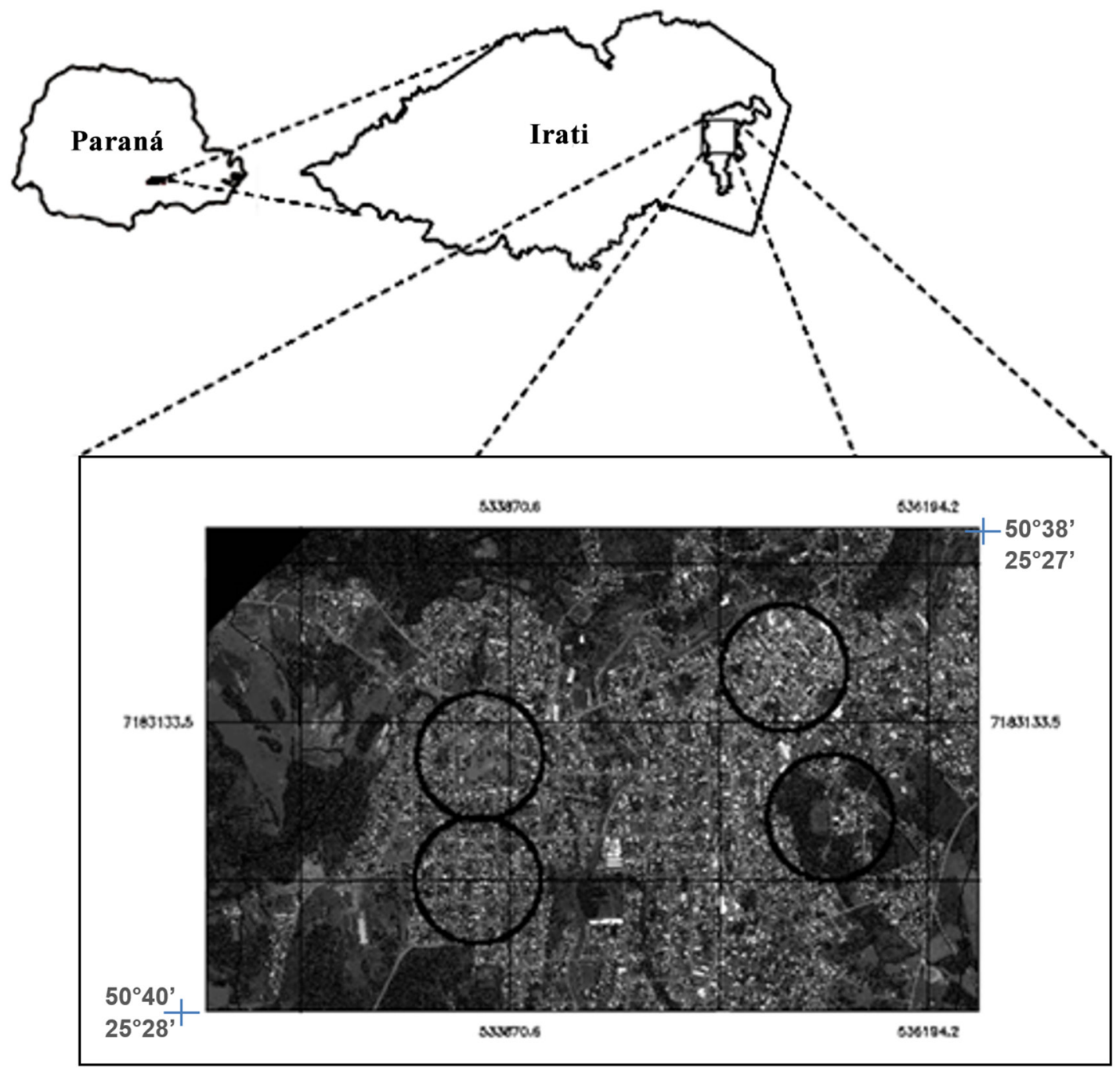

Sistema UTM 2 - Datum Horizontal Sirgas 2000

Figura 1. Imagem, obtida pelo satélite Quickbird, da parte central da cidade de Irati, 2011, estado do Paraná, evidenciando as quatro áreas amostrais utilizadas na pesquisa.

Figure 1. Study area showing the Quickbird satellite image of the central part of the Irati city, 2011, Paraná State, showing the four sampling areas used in the research. 
direta com colunas de mercúrio, com precisão de $3 \%$ (para mais ou para menos), marca Inconterm. Esses aparelhos são utilizados para indicar a temperatura e umidade relativa do ar de forma analógica, o que permite uma maior confiabilidade dos dados, mesmo que as leituras precisem ser repetidas por vários dias em horários predeterminados. Antes da instalação dos miniabrigos com esses aparelhos, os mesmos foram devidamente ajustados, buscando dirimir qualquer diferença decorrente das sucessivas leituras. Para tanto, todos os aparelhos utilizados foram colocados em um mesmo ambiente por um período de três dias e os dados foram coletados de maneira a simular a coleta a ser feita em campo, seguindo os procedimentos descritos por Danni-Oliveira (2002), ou seja, adaptados em abrigos termométricos e instalados dentro de suportes de madeira, de forma a evitar o contato direto com os raios solares. As medições foram realizadas nos dias 01, 04, 07 e 13/03/2012, todos os dias secos e de verão, nos horários das 06:00, 09:00, 15:00 e 21:00 horas.

\subsection{Análise de dados}

No delineamento experimental do presente estudo consideraram-se dois fatores hierarquizados. $\mathrm{O}$ fator principal ou condicionante foram as áreas de estudo (Área 1, Área 2, Área 3 e Área 4) e os horários de registro $(6,9,15$ e 21 horas), formaram o segundo fator. As variáveis dependentes foram a umidade relativa do ar e a temperatura. Como o período de amostragem foi de 4 dias, cada dia foi considerado uma repetição. Assim, as diferenças de temperatura e umidade foram averiguadas, estatisticamente, mediante uma anova hierarquizada, entre as áreas delimitadas e os períodos do dia. Quando apontada significância na anova, as médias foram contrastadas pelo teste de Tukey.

As premissas de homogeneidade de variância e gaussianidade foram checadas mediante os testes de Bartlett e Kormogorov-Smirnov, respectivamente (Zar, 1999). Em todas as análises foi considerado um a (nível de significância) de 5\%. Para determinar de forma multivariada a ordenação das áreas de estudo em função do uso e cobertura da terra e suas respectivas temperaturas e umidades optou-se por utilizar, além das anovas, uma análise de componentes principais (ACP). A ACP consiste em uma técnica multivariada de análise de ordenação. Assim, são gerados componentes principais que explicam determinada porção da variação total dos dados (Johnson \& Wichern, 1988). Dessa forma, foi possível averiguar como as áreas ficam ordenadas no espaço, e que variáveis, em que horário, mais influenciaram a ordenação encontrada.

O número de componentes principais foi determinado pelo critério das raízes latentes, também conhecido como critério de Kaiser e os autovetores e autovalores foram extraídos da matriz de correlação para evitar distorções (Johnson \& Wichern, 1988).

\section{RESULTADOS E DISCUSSÃO}

\subsection{Cobertura e uso da terra}

Os resultados espaciais da análise interpretativa das imagens orbitais, destacando as 4 áreas amostrais são apresentados na Figura 2, assim como os Índices de cobertura arbórea, rasteira, corpos d'água e áreas construídas são apresentados na Tabela 1.

Com os resultados da Tabela 1, conclui-se que a área 1 possui mais da metade de sua área coberta por vegetação arbórea, ultrapassando o índice de áreas

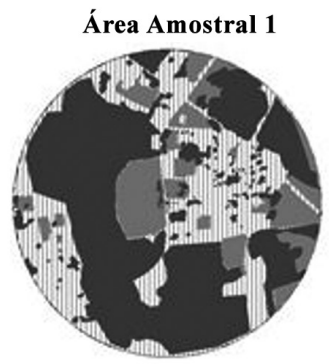

Área Amostral 3

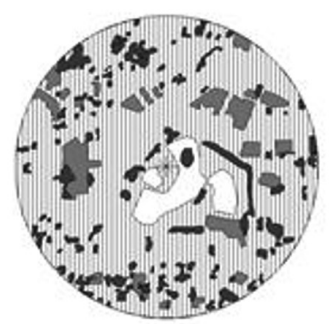

DÁrea Construída Corpos d'água Vegetação Rasteira Vegetação Arbórea

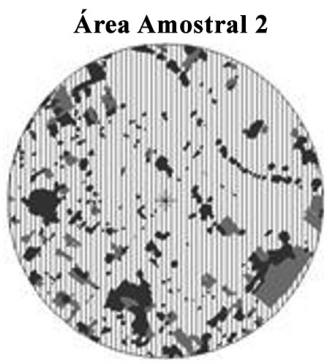

Área Amostral 4

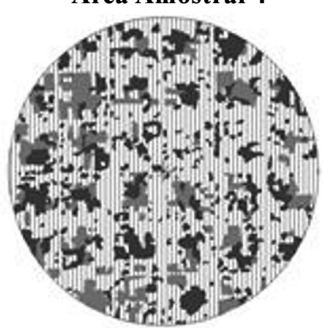

igura 2. Índices de cobertura arbórea, rasteira, corpos d'água e áreas construídas, cidade de Irati-PR, 2011.

Figure 2. Indices of tree cover, ground, water bodies and areas built, Irati City, 2011. 
construídas, sendo portanto, teoricamente, a que apresenta o microclima mais agradável, ou seja com temperaturas mais amenas e uma umidade relativa do ar distante dos extremos. A área 2 apresenta um índice baixo de cobertura por áreas verdes em relação ao de áreas construídas. A área 3 apresenta um índice geral de cobertura de vegetação baixo, porém, espera-se que o microclima seja mais agradável que na área 2 devido à presença de um lago, ou seja, uma superfície representativa de corpos d'água. A área 4 apresenta um índice de cobertura de vegetação bem maior que as áreas 2 e 3, além de apresentar a melhor distribuição espacial das áreas verdes, considerando a soma dos índices de vegetação arbórea e rasteira.

\subsection{Relações do uso e cobertura da terra com a temperatura e umidade relativa do ar}

Os valores médios de temperatura e umidade podem ser observados na Figura 2. De forma geral, as duas variáveis oscilaram significativamente entre as áreas, em um mesmo horário, e dentro das áreas, nos diferentes horários (temperatura $\mathrm{F}_{12,48}=10,64 ; \mathrm{p}>0,01$ e umidade $\mathrm{F}_{12,48}=3,18 ; \mathrm{p}>0,01$ ).

Especificamente, segundo os resultados apresentados nas Figuras 3 e 4, houve um acréscimo de temperatura das 6 da manhã até as 15 horas, sendo que entre 9 e 15 horas o aumento da temperatura foi significativo (as barras no gráfico não se tocam) em todas as áreas, com exceção, apenas, para a área 1, que representa o trecho com maior vegetação. Entre as 15 e 21 horas houve um decréscimo de temperatura e, novamente, apenas na área 1 não foi registrado decréscimo significativo.

Outro resultado importante (Figura 3) é que há diferença significativa entre as áreas no horário mais quente amostrado no presente estudo, pois às 15 horas,

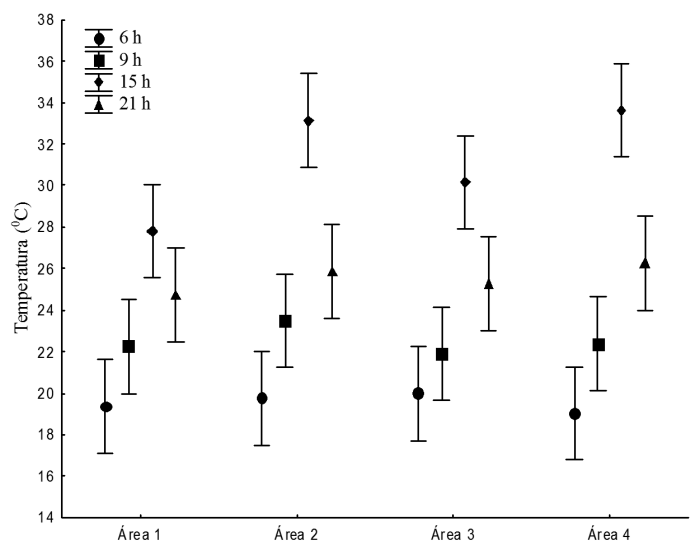

Figura 3. Médias e diferenças médias significativas para o teste de Tukey, a 5\% de temperatura média do ar, de 4 trechos com diferentes usos e coberturas da terra da cidade de Irati-PR, 2012.

Figure 3. Means and significant mean differences for Tukey test at $5 \%$ of temperature of 4 sites with different land use in Irati-PR, 2012.

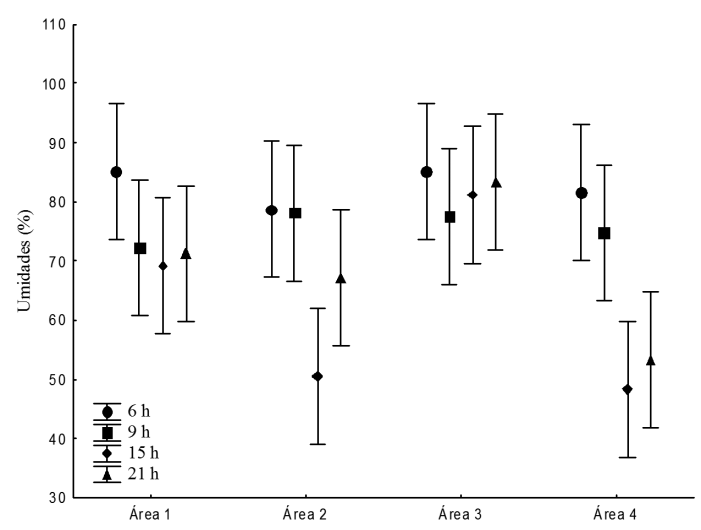

Figura 4. Médias e diferenças médias significativas para o teste de Tukey, a 5\% de umidade relativa, de 4 trechos com diferentes usos e coberturas da terra da cidade de Irati-PR, 2012.

Figure 4. Means and significant mean differences for Tukey test at $5 \%$ of and humidity of 4 sites with different land use in Irati-PR, 2012.

Tabela 1. Índices de cobertura arbórea, rasteira, corpos d'água e áreas construídas, cidade de Irati-PR, 2011. Table 1. Indices of tree cover, ground, water bodies and areas built, Irati City, 2011.

\begin{tabular}{|c|c|c|c|c|c|c|c|c|}
\hline & \multicolumn{2}{|c|}{ Área 1} & \multicolumn{2}{|c|}{ Área 2} & \multicolumn{2}{|c|}{ Área 3} & \multicolumn{2}{|c|}{ Área 4} \\
\hline & $\mathrm{Km}^{2}$ & $\%$ & $\mathrm{Km}^{2}$ & $\%$ & $\mathrm{Km}^{2}$ & $\%$ & $\mathrm{Km}^{2}$ & $\%$ \\
\hline $\begin{array}{c}\text { Índice de } \\
\text { vegetação arbórea }\end{array}$ & 0,200930 & 52,2 & 0,048316 & 12,6 & 0,035541 & 9,2 & 0,079688 & 20,7 \\
\hline $\begin{array}{c}\text { Índice de } \\
\text { vegetação rasteira }\end{array}$ & 0,056446 & 14,7 & 0,027043 & 7,0 & 0,029581 & 7,7 & 0,046818 & 12,2 \\
\hline Corpos d’água & 0,000000 & 0,0 & 0,000000 & 0,0 & 0,020560 & 5,3 & 0,000000 & 0,0 \\
\hline Áreas construídas & 0,127356 & 33,10 & 0,309184 & 80,4 & 0,299091 & 77,7 & 0,258080 & 67,1 \\
\hline TOTAL & 0,384732 & 100 & 0,384543 & 100 & 0,384772 & 100 & 0,384586 & 100 \\
\hline
\end{tabular}


a média da área $1\left(27,80^{\circ} \mathrm{C}\right)$ é significativamente inferior a das áreas com maior cobertura urbana (área $2=33,12{ }^{\circ} \mathrm{C}$ e área $4=33,62^{\circ} \mathrm{C}$ ).

As menores médias de umidade relativa do ar (Figura 4) foram verificadas às 15 horas e os valores mais altos às $6 \mathrm{~h}$. As maiores amplitudes são verificadas nas áreas mais urbanas (2 e 4), conforme ocorreu com a temperatura. Ainda é possível demostrar que existem diferenças significativas de umidade entre as 9 e 15 horas nas áreas 2 e 4.

Os principais motivos para essas oscilações de temperatura e umidade estão relacionados à alta concentração de áreas verdes que ocorre na área amostral 1 e nos corpos d'água da área 3 (Tabela 2). Jardim (2011), em estudo realizado em áreas urbanas e periurbanas da cidade de São Paulo, também verificou que a umidade do ar é superior em áreas urbanas vegetadas. Portanto, as fontes de produção de vapor associada à presença de vegetação, elemento fortemente representativo do trecho 1 , é um fator de influência na umidade do ar e na temperatura.

Além do presente estudo, outros trabalhos já comprovaram a existência de ilhas de calor em aglomerados urbanos menores que os verificados na grande São Paulo. Maio et al. (2012), na cidade de Pelotas (RS), encontraram temperaturas mais elevadas em áreas densamente urbanizadas que nas regiões periurbanas, devido a presença de arroios e várzeas.

De fato, no presente estudo, o uso e ocupação da terra influenciaram significativamente o microclima da cidade, pois a densidade de área construída que impede a ventilação, e o aumento da cobertura urbana com concreto e asfalto, materiais que possuem uma elevada capacidade para absorver calor, são os responsáveis pelas diferenças de temperatura e umidade encontradas neste estudo. Tal afirmativa é confirmada pela análise de componentes principais (Figura 5 e
Tabela 2). Mediante a ordenação, é possível verificar que existem 4 grandes agrupamentos formados pelos quatro pontos amostrados (Figura 5), e que dentre as variáveis amostradas, a que mais tem influência em tal ordenação são as áreas construídas, seguidas da porcentagem de arbóreas e rasteiras (Tabela 2). Os corpos de água apresentaram maiores correlações com as componentes 2 e 3 , influenciando, também significativamente, a umidade e temperatura, isso porque com maiores temperaturas, maior a evaporação de água e, consequentemente, maior elevação da umidade, já que as 3 primeiras componentes principais é que apresentaram autovalor maior que 1 (Tabela 2).

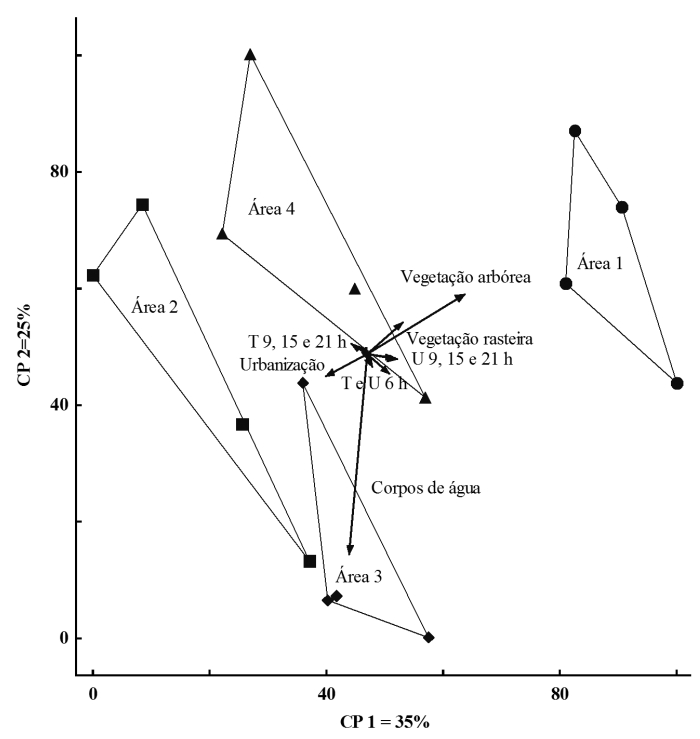

Figura 5. Análise de Componentes Principais em função de temperaturas e umidades para 4 áreas com diferentes coberturas da terra no município de Irati-PR, 2012.

Figure 5. Principal Component Analysis in terms of temperatures and humidities for 4 areas with different land cover in the municipality of Irati - PR, 2012.

Tabela 2. Correlações das variáveis de uso e ocupação da terra de trechos de Irati-PR, com as três primeiras componentes principais, 2012.

Table 2. Loading between land use in Irati - PR, and the first three principal components, 2012.

\begin{tabular}{cccc} 
Uso e ocupação da terra & $\mathbf{C P ~ 1}$ & $\mathbf{C P} \mathbf{2}$ & $\mathbf{C P ~ 3}$ \\
\hline Vegetação arbórea (\%) & $\boldsymbol{\lambda}=\mathbf{4 , 2 7}$ & $\boldsymbol{\lambda}=\mathbf{3 , 0 6}$ & $\boldsymbol{\lambda}=\mathbf{2 , 0 8}$ \\
\hline Corpos d'água (\%) & 0,82 & 0,49 & 0,20 \\
Urbanização (\%) & $-0,10$ & 0,67 & 0,62 \\
Vegetação rasteira (\%) & $-0,85$ & $-0,45$ & 0,13 \\
\hline
\end{tabular}


Quanto aos valores de temperatura e umidade registrados nos diferentes períodos, é possível discriminar, mediante a análise de componentes principais, que os períodos de 9, 15 e 21 horas são os que mais contribuem para explicar as oscilações provocadas pelo uso e ocupação da terra (Figura 4). A temperatura e umidade às 6 horas estão mais correlacionadas com o $3^{\circ}$ componente principal e, mesmo assim, de forma fraca $(r=0,04)$.

\section{CONCLUSÕES}

- A partir dos resultados obtidos, podemos concluir que as características das áreas amostradas influenciam nas temperaturas diárias e estas, na umidade relativa, principalmente nos horários de maior incidência solar;

- A aplicação da análise de agrupamento permitiu maior evidência sobre as diferenças de uso e ocupação do solo urbano de cada uma das áreas amostrais utilizadas no estudo;

- Os valores calculados para os índices de cobertura arbórea e áreas verdes das áreas amostrais, revelamse diretamente proporcionais aos resultados obtidos na aplicação da estatística pela análise de agrupamento;

- O único local com correlação significativa entre temperatura e umidade relativa foi o ponto amostral $4(\mathrm{r}=-0,60)$, isso pode ser explicado pela melhor distribuição espacial das áreas verdes (arbóreas e não arbóreas).

\section{AGRADECIMENTOS}

Os autores agradecem à Fundação Araucária pelo apoio à pesquisa.

\section{STATUS DA SUBMISSÃO}

Recebido: 21 out., 2014

Aceito: 1 jun., 2015

\section{AUTOR(ES) PARA CORRESPONDÊNCIA}

\section{Paulo Costa de Oliveira Filho}

Departamento de Engenharia Ambiental, Universidade Estadual do Centro-Oeste UNICENTRO-PR, Rodovia PR153, Km 07, Riozinho, CP 21, CEP 84500-000, Irati, PR, Brasil e-mail: paulocostafh@gmail.com

\section{REFERÊNCIAS}

Andrade AR, Pottker GS, Oliveira PC Fo, Machado ALF. Influence of land use on urban climate of a small town. Acta Scientiarum. Technology 2013; 35(2): 349-361. http:// dx.doi.org/10.4025/actascitechnol.v35i2.13703.

Ayoade JO. Introdução à climatologia para os trópicos. Rio de Janeiro: Bertrand Brasil; 1998.

Cantat O. Líolt de chaleur urbain parisien selon les 'types de temps. Norois 2004; 191: 75-102.

Danni-Oliveira IM. Procedimentos de aferição de termômetros para atividades de campo em climatologia geográfica. Revista RA'E GA, Curitiba 2002; 6: 75-80.

Instituto Agronômico do Paraná - IAPAR [online]. [citado em 2014 Mar]. Disponível em: http://www.iapar.br/ modules/conteudo/conteudo.php? conteudo $=677$

Instituto Brasileiro de Geografia e Estatística - IBGE [online]. [citado em 2014 Mar]. Disponível em: http:// cidades.ibge.gov.br/xtras/perfil.php?lang=\&codmun $=4$ 11070\&search=parana|irati|infograficos:-informacoescompletas

Jardim CH. Relações entre temperatura, umidade relativa do ar e pressão atmosférica em área urbana: comparação horária entre dois bairros no município de São Paulo-SP. Geografias 2011; 12: 128-142.

Johnson RA, Wichern DW. Applied multivariate analysis. Englewood Clifs: Prentice Hall; 1988. 607 p.

Lombardo M.A. O clima e a cidade. São Paulo: Hucitec; 1985. Lombardo MA. O clima e a cidade. In: Encontro Nacional do Ambiente Construído - ANTAC; 1997; Salvador.

Maio BM, Collischonn E, Mattos GP. Comportamento noturno de temperatura e umidade do ar na cidade de Pelotas/RS sob diferentes condições de tempo. Revista Geonorte 2012; 1: 257-270.

Rodríguez ACM, Hernandez P Fo, Moreira MA. Mapeamento multitemporal do uso e cobertura do solo do município de São Sebastião-SP, utilizando técnicas de segmentação e classificação de imagens TM-Landsat e HRV-SPOT. São José dos Campos: INPE; 2000.

Teza CTV, Baptista GMM. Identificação do fenômeno ilhas urbanas de calor por meio de dados ASTER on demand 08 - Kinetic Temperature (III): metrópoles brasileiras. In: Anais do Simpósio Brasileiro de Sensoriamento Remoto; 2005; Goiânia. Goiânia: INPE; 2005. p. 3911-3918.

Zar JH. Biostatistical analysis. New Jarsey: Prentice-Hall; 1999. 